\begin{tabular}{|l|l|}
\hline Postprint Version & 1.0 \\
\hline Journal website & $\underline{\text { http://www3.interscience.wiley.com/journal/122267619/abstract }}$ \\
\hline Pubmed link & $\underline{\text { http://www.ncbi.nlm.nih.gov/pubmed/19335495 }}$ \\
\hline DOI & $10.1111 / \mathrm{j} .1365-2753.2008 .01012$ \\
\hline
\end{tabular}

This is a NIVEL certified Post Print, more info at http://www.nivel.eu

\title{
Management of urinary incontinence in general practice: data from the Second Dutch National Survey
}

\author{
MaAike A.G. VAn GerWEn MD, ${ }^{1}$ Francois G. SCHELleVIS MD PhD ${ }^{2}$ AND ANTOINE L.M. LAGRO- \\ JANSSEN MD PHD ${ }^{3}$ \\ ${ }^{1}$ Doctor, Department of General Practice, Radboud University Nijmegen Medical Centre, Amsterdam, the \\ Netherlands \\ ${ }^{2}$ Professor, Doctor, Nivel, Netherlands Institute for Health Services Research and Department of General \\ Practice/EMGO Institute; Vrije Universiteit Medical Centre, Amsterdam, the Netherlands \\ ${ }^{3}$ Professor, Doctor, Radboud University Nijmegen Medical Centre, Nijmegen, the Netherlands \\ Correspondence to Prof Dr Antoine L.M. Lagro-Janssen \\ E-mail: a.lagro-janssen@hag.umcn.nl
}

\begin{abstract}
Objective The aim of this study was to provide insight into the referral pattern of newly diagnosed patients with urinary incontinence in general practice and into the prescription of medication and incontinence pads by general practitioners (GPs). We also examined the influence of gender and age of patient/GP on these patterns.

Methods Data were obtained from the Second Dutch National Survey of General Practice. We used registered new episodes for urinary incontinence of patients of 25 years and older in the year 2001 and examined the initial management.

Results Twelve per cent of the patients were referred to a physiotherapist, $2.4 \%$ to a gynaecologist and $2.9 \%$ to a urologist. Medication was prescribed to $9.8 \%$ and $12.7 \%$ received incontinence pads. The number of female patients referred decreased significantly after 60 years of age and the number of incontinence pads and medication prescribed was higher in this age patient group. Gender of the GP did not influence the prescription or referral rate. Male patients were significantly less frequently referred than female patients.

Conclusion The lower referral rate and higher prescription rate of incontinence pads and medication at older age indicate that GPs are not sufficiently aware of the benefits of pelvic floor muscle training and bladder training at older age.

We did not find an influence of gender of the GP on management of urinary incontinence, unlike previous research. GPs were reluctant in prescribing medication, which is in agreement with national and international guidelines.

\section{INTRODUCTION}

Urinary incontinence is a widespread, troubling condition in men and women. In people aged 60 years and older living at home, $29 \%$ of the women are incontinent and $10 \%$ of the men [1]. Furthermore, in community-dwelling women of 20 years and older, $25 \%$ reports urine leakage and $7 \%$ significant incontinence defined as moderate or severe incontinence that is experienced as bothersome [2]. In the elderly, more patients suffer from urinary incontinence compared with the younger population. So, with the ageing of the population, urinary incontinence will become even more prevalent.

General practitioners (GPs) have reported to experience barriers to perform high quality of care in the management of urinary incontinence in daily general practice, especially in the elderly [3]. They feel that they have little therapeutic options or they think that non-invasive treatment will not work. GPs sometimes suggest that older people are not motivated enough to perform exercises and training [3]. It is therefore relevant to see if the age of the patient affects the actual management of urinary incontinence by GPs.
\end{abstract}


Gerwen, M.A.G. van, Schellevis, F.G., Lagro-Janssen, A.L.M. Management of urinary incontinence in genera practice: data from the second Dutch National Survey. Journal of Evaluation in Clinical Practice: 2009 15(2) 341-345

Because non-invasive therapies such as pelvic floor muscle training for stress incontinence and bladder training for urge incontinence are very effective at any age [4].

Incontinence has a great impact on both health and quality of life. Two in three women and about half of the men with urinary incontinence experience a negative influence on their quality of life [5]. Men consult their GP when having less severe urinary incontinence compared with women [6]. This help-seeking behaviour in men is mostly related to the distress experienced in daily life [7].

Former research indicated that the gender of the GP might influence the management of urinary incontinence. Lagro-Janssen et al. found that female GPs seemed to refer more patients to a specialist (for urodynamic evaluation) or a physiotherapist [8]. They also prescribed more frequently oestrogens to older female patients. Male GPs treated more patients themselves and prescribed more spasmolytics. Elderen et al. confirmed the influence of gender of the GP on consulting behaviour [9].

The aim of this study was to provide insight into the initial management (referral to physiotherapist or specialists and prescription of incontinence pads or medication) of newly diagnosed patients with urinary incontinence in general practice. Because gender and age of GP and patient seemed to have influence on the management of urinary incontinence as concluded in previous research, we also explored the gender and age related differences in these management patterns.

\section{MATERIALS AND METHODS}

The data for this study were obtained from the Second Dutch National Survey of General Practice (DNSGP-2), performed in 2001 with a time frame of 12 months [10]. The aim of this survey was to provide nationally representative information on morbidity in the Dutch population as presented to GPs, the use of health services, health determinants and socio-demographic characteristics. In the Netherlands general practice is accessible to all and therefore is an optimal setting for providing this information. GPs act as gatekeeper in the health care system, so patients have only access to specialized medical care after referral by a GP. Also, all non-institutionalized Dutch citizens are registered with a GP and the GP holds a lifelong record of his/her patients.

\section{Study population}

DNSGP-2 was carried out in 104 general practices, comprising 195 GPs (in total 165.5 GPs full-time equivalents). Eventually eight practices were excluded from the database because of incomplete data collection on morbidity. The remaining 96 practices were representative for the Netherlands. No statistically significant differences were found for gender and age of the GP, region of residence or urbanization level. Only GPs working as soloist were underrepresented (32\% versus $44 \%$ overall). The listed patients in the practices included a cohort of almost 390000 patients. These patients were representative for the Dutch population based on age, gender and type of health care insurance (public/private).

Data extracted from the electronic medical records of all patients registered in the participating practices included the presented morbidity in the study year (2001). Contact diagnoses were coded according to the International Classification of Primary Care (ICPC) [10]. The GPs in the study were experienced in working with this ICPC coding system. This contact registration resulted in a database with roughly 1.6 million contacts, clustered in approximately 950000 episodes of care.

For our research, we used a population of 25 years and older in order to exclude incontinence problems in children and adolescents which mainly derive from different causes.

\section{Data}

From the 96 practices the following data of patients of 25 years and older were used:

- registered first episodes of care for urinary incontinence (ICPC-core U04) with the GP within the year of study (2001);

- initial management (in the first 3 months after newly diagnosed urinary incontinence): prescriptions of medication for urinary incontinence (flavoxate; oxybutynin; tolterodin; oestriol); prescription of incontinence pads; referrals to gynaecologist, urologist or physiotherapist;

- patients characteristics: age, gender, and

- general practitioners characteristics: gender.

We calculated the proportion of patients diagnosed with incontinence which were referred to a medical specialist or physiotherapist separately for male and female GPs, male and female patients and by age group of female patients. For the age group calculations, we only used female patients, because of the 
Gerwen, M.A.G. van, Schellevis, F.G., Lagro-Janssen, A.L.M. Management of urinary incontinence in genera practice: data from the second Dutch National Survey. Journal of Evaluation in Clinical Practice: $2009,15(2)$ 341-345

disproportionate male-female ratio (one man in every five women). The same calculations were made for the prescription of medication for incontinence and of incontinence pads.

\section{Statistics}

Odds ratios and confidence intervals were calculated using the SAS-procedure PROC GLIMMIX (a multilevel logistic model). This model takes into account the hierarchical structure of patients nested within general practices and adjusts the confidence intervals for this clustering.

\section{RESULTS}

Our research population consisted of 631 patients who were diagnosed by their GP the first time with urinary incontinence; 112 men and 519 women. Forty-four per cent of the patients were between 25 and 59 years of age, $27 \%$ between 60 and 74 and $29 \%$ were 75 years and older. Twenty-one per cent of the patients were diagnosed and treated by a female GP and $79 \%$ by a male GP.

Of our research population, $16.0 \%$ was referred to a urologist, gynaecologist or physiotherapist; $9.8 \%$ received a prescription for medication, $12.7 \%$ received incontinence pads, $1.6 \%$ was referred and received medication and $0.6 \%$ received medication and incontinence pads.

During the first 3 months after diagnosis, eight patients $(2.1 \%)$ had three or more consultations regarding urinary incontinence with the GP.

Of the referred patients, one out of eight patients of 25 years and older was referred to a physiotherapist, $2.4 \%$ to a gynaecologist and $2.9 \%$ to a urologist.

There was no difference between the prescription of medication, like flavoxate, oxybutynin, tolterodin or oestriol, to male or female patients nor played the gender of the GP a role in medication prescription.

(Tables $1 \& 2$ ) Older women with urinary incontinence received more medication compared with younger patients $(<60$ years). (Table 3$)$

\section{[TABLE 1]}

\section{[TABLE 2]}

\section{[TABLE 3]}

The intra class coefficient was 0.0927 .

There was no difference between the prescription frequency of incontinence pads to men or women, nor played the gender of the GP a role (Tables $1 \& 2$ ). Above 60 years of age, women received more prescriptions for incontinence pads, compared with younger women (Table 3 ).

The intra class coefficient was 0.4242 .

Female and male GPs equally referred patients in the first 3 months after diagnosing urinary incontinence, $17.7 \%$ respectively $15.7 \%$ (Table 1 ). However, there was a significant difference in referrals between male and female patients, where $7.1 \%$ of the men and $19.5 \%$ of the women were referred (Table 2). Women aged 60 years and older were referred less frequently than younger women (Table 3 ).

The intra class coefficient was 0.1935 .

\section{DISCUSSION}

\section{Main findings}

GPs referred only $12 \%$ of the patients with urinary incontinence to a physiotherapist. Regarding all referrals more women than men were referred and more patients younger than 60 years of age. We found that Dutch GPs were reluctant to prescribe medication for urinary incontinence which is in agreement with national and international guidelines for urinary incontinence [11-14]. However, older women received more frequently medication than younger women. Incontinence pads were prescribed often especially to elderly women as only 'treatment'. We found that more women of 60 years and older received incontinence pads from their GP, compared with younger patients. This number will decrease if older patients are treated for urinary incontinence with physiotherapy. Gender of the GP, had no influence on the initial management of urinary incontinence. 
Gerwen, M.A.G. van, Schellevis, F.G., Lagro-Janssen, A.L.M. Management of urinary incontinence in genera practice: data from the second Dutch National Survey. Journal of Evaluation in Clinical Practice: $2009,15(2)$ 341-345

\section{Strengths and limitations of the study}

Our study provides a good representation of the initial management of urinary incontinence in Dutch general practice because of the large database on morbidity data provided by the DNSGP-2. A limitation of our study was the inability to determine the initial management of male patients with urinary incontinence by age group. For this the number of male patients was too low. Another limitation was that we had no insight in the number of patients who used incontinence pads without interference of the GP, for instance by buying incontinence pads at the pharmacy or drug store. The number of patients using incontinence pads is probably higher than we found in our study. This could also be a possible explanation for the large proportion of incontinent patients (about 60\%) in our study who did not receive any 'initial treatment' at all from their GP.

\section{Comparison with existing literature}

Regarding the management of urinary incontinence, the conclusion of a recently performed systematic review emphasized that non-invasive measures for urinary incontinence are effective, also in the elderly [4]. As a consequence, patients with stress incontinence could be treated with pelvic floor muscle treatment and patients with urge incontinence with bladder training. A combination of both therapies is successful for mixed incontinence. Because most GPs have stated in former research to have little time for proper management of urinary incontinence [3], it is preferable for GPs to refer patients with urinary incontinence, also elderly patients, to a physiotherapist for adequate education and treatment. However, we found that the number of referrals is small and that older women are less frequently referred than younger women. The low number of referrals might imply that for instance a nurse practitioner or the GP him/herself gives instructions about bladder training or pelvic floor muscle treatment to the incontinent patient. However, it seems more likely that the GP has another approach in managing urinary incontinence (prescribing incontinence pads or medication or having an expectant treatment) because co-morbidity in the elderly such as genito-urinary prolaps in women or dementia can complicate the non-invasive treatment.

We found that only $2.1 \%$ of the patients saw their GP for two or more follow-up consultations within the first 3 months. According to the Dutch national guidelines for urinary incontinence, when starting noninvasive treatment for urge-, stress- or mixed incontinence at least two follow-up consultations are necessary in the first 3 months ( 2 and 6 weeks after the initial consultation) [11]. After 3 months of noninvasive treatment (pelvic floor muscle training and/or bladder training), an evaluation of the effectiveness is recommended. Following our results, the number of GPs instructing patients about non-invasive treatment is very low. It is possible that a registered nurse within the practice follows these patients. However, it is not common practice in the Netherlands that every general practice has a nurse on staff which performs these consultations. Therefore, it can be concluded that few GPs instruct their patients about non-invasive treatment themselves.

In our study, the gender of the doctor had no influence on the initial management of urinary incontinence in general practice. Referral to specialist or physiotherapist and prescribing medication or incontinence pads did not depend on the gender of the GP. However, Lagro-Janssen et al. found differences in the prescribing pattern between male and female GPs whereas, male GPs prescribed more frequently spasmolytics to women with urinary incontinence and female GPs more oestrogens [8]. In our research, we were not able to distinguish between the different drugs because of the small prescription numbers. Therefore, it is possible that we lost the difference in prescribing pattern between male and female GPs. Lagro-Janssen et al. also found that female GPs refer more patients for urodynamic evaluation to a specialist or for treatment to a physiotherapist [8]. Lagro-Janssen et al. performed their research shortly after the first introduction of the Dutch guideline 'urinary incontinence' for GPs, which advices in management of urinary incontinence in general practice. It is possible that since then and with the introduction of the new guideline in 2006 more GPs, male and female, are better informed about the recommendations made in this guideline and that therefore the number of referrals to specialists and prescriptions of medication have decreased. Another study concluded that although experienced female general practitioners instruct more patients in pelvic floor exercises, prescribe more oestrogens and refer more patients, patient management is largely independent of the doctors' sex and age [15]. This is an agreement with our study.

We found that male patients were less frequently referred then female patients with urinary incontinence. This is an interesting finding what could be related to the fact that men consult their GP sooner with less severe incontinence compared with women. However, further research on GPs motives for referring male incontinent patients differently than female patients could give an explanation for the more 'wait-and-see' approach in men? 
Gerwen, M.A.G. van, Schellevis, F.G., Lagro-Janssen, A.L.M. Management of urinary incontinence in genera practice: data from the second Dutch National Survey. Journal of Evaluation in Clinical Practice: $2009,15(2)$ 341-345

In agreement with national and international guidelines, Dutch GPs are reluctant to prescribe medication as initial treatment for urinary incontinence. In the last version of the Dutch national guideline for GPs, no recommendations for drug therapy for stress incontinence were made. Oral and vaginal oestrogens are no longer advised in the management of urinary incontinence. In case of urge incontinence after failure of bladder training, anti-cholinergic medication remains optional, however is not the first recommended treatment option [11].

We found in high intra class coefficient in prescribing incontinence pads between practices. This can be due to the fact that doctors in one practice give more prescriptions for incontinence pads compared with other practices. However, a second and more reasonable explanation is that in some practices the prescription of incontinence pads is probably better registered than in other practices.

\section{Implications for clinical practice}

In conclusion, it seems that Dutch GPs prescribe incontinence pads too frequently and refer too little to physiotherapists for urinary incontinence especially in the elderly population. Because urinary incontinence is more common in patients above 60 years of age and the problem becomes more complex, the GP should refer an older patient with urinary incontinence more frequently to a physiotherapist or a specialized nurse for non-invasive management of urinary incontinence. They have the knowledge and time to explain, advice and treat patients with urinary incontinence. If these patients are treated well, the use of incontinence pads will decrease. A successful approach therefore will lower the costs and increases the quality of life of older people with urinary incontinence.

\section{ACKNOWLEDGEMENT}

We thank Hans Bor, statistician, for his help with the statistical analyses.

\section{REFERENCES}

1. Teunissen, T. A. M., Van den Bosch, W. J. H. M., Van den Hoogen, H. J. M. \& Lagro-Janssen, A. L. M. (2004) Prevalence of urinary, fecal and double incontinence in the elderly living at home. International Urogynecology Journal, 15, 10-13.

2. Hannestad, Y. S., Rortveit, G., Sandvik, H. \& Hunskaar, S. (2000) A community-based epidemiological survey of female urinary incontinence: the Norwegian EPINCONT study. Journal of Clinical Epidemiology, $53,1150-1157$.

3. Teunissen, T. A. M., Van den Bosch, W. J. H. M., Van Weel, C. \& Lagro-Janssen, A. L. M. (2006) Urinary incontinence in the elderly: attitudes and experiences of general practitioners. A focus group study. Scandinavian Journal of Primary Health Care, 24 (1), 56-61.

4. Teunissen, T. A. M., De Jonge, A., Van Weel, C. \& Lagro-Janssen, A. L. M. (2004) Treatment of urinary incontinence in the community-based elderly- conservative measures that work: a systematic review. The Journal of Family Practice, 53, 25-31.

5. Temml, C., Haidinger, G., Schmidbauer, J., Schatzl, G. \& Maderbacher, S. (2000) Urinary incontinence in both sexes: prevalence rates and impact on quality of life and sexual life. Neurourology and Urodynamics, 19, 259-271.

6. Teunissen, D., Van den Bosch, W., Van Weel, C. \& Lagro-Janssen, T. (2006) 'It can always happen': the impact of urinary incontinence on elderly men and women. Scandinavian Journal of Primary Health Care, 24, 166-173.

7. Teunissen, D. \& Lagro-Janssen, T. (2004) Urinary incontinence in community dwelling elderly: are there sex-differences in help-seeking behaviour? Scandinavian Journal of Primary Health Care, 22, 209-216.

8. Lagro-Janssen, A. L. M. \& Liberton, I. J. W. (1996) Sekseverschillen in de aanpak van urineincontinentie bij vrouwen [Sex differences in the approach of urinary incontinence in women]. Huisarts nu, 2, 53-58.

9. Van Elderen, T., Maes, S., Rouneau, C. \& Seegers, G. (1998) Perceived gender difference in physician consulting behaviour during internal examination. Family Practice, 15, 147-152.

10. Westert, G. P., Schellevis, F. G., De Bakker, D. H., Groenewegen, P. P., Bensing, J. M. \& Van der Zee, J. (2005) Monitoring health inequalities through general practice: the Second Dutch National Survey of General Practice. European Journal of Public Health, 15, 59-65.

11. Lagro-Janssen, A. L. M., Breedveldt Boer, H. P., Van Dongen, J. J. A. M., Lemain, T. J. J., Teunissen, D. \& Van Pinxteren, P. (2006) NHG standaard Incontinentie voor urine (Dutch guidelines for GPs: urinary incontinence). Huisarts en Wetenschap, 49, 501-510. 
Gerwen, M.A.G. van, Schellevis, F.G., Lagro-Janssen, A.L.M. Management of urinary incontinence in genera practice: data from the second Dutch National Survey. Journal of Evaluation in Clinical Practice: $2009,15(2)$ 341-345

12. Scottish Intercollegiate Guidelines Network. (2004) Management of Urinary Incontinence in Primary Care, a National Clinical Guideline. Edinburgh: Royal College of Physicians.ISBN 1899893148.

Available from http://www.sign.ac.uk/pdf/sign79.pdf (accessed 13 March 2009).

13. Agency for Health Care Policy and Research (1996) Urinary incontinence in adults: acute and chronic management. Clinical Practice guideline No 2, update. AHCPR.

14. Corcos, J., Gajewski, J., Heritz, D., Patrick, A., Reid, I., Schick, E. \& Stothers, L. (2006) Canadian Urological Association guidelines on urinary incontinence. The Canadian Journal of Urology, 13, 31273138.

15. Sandvik, H. \& Hunskaar, S. (1990) Doctors' characteristics and practice patterns in general practice: an analysis based on management of urinary incontinence. Scandinavian Journal of Primary Health Care, 8 , 179-182.

\section{TABLES}

Table 1 Relation between GPs gender and initial management of patients with urinary incontinence $(>25$ years) during the first 3 months after the diagnosis; percentages and OR (F/M)

\begin{tabular}{|c|c|c|c|}
\hline & \multicolumn{2}{|c|}{ Gender GP (\%) } & \multirow[b]{2}{*}{ OR (95\% CI) } \\
\hline & $M(n=497)$ & $F(n=134)$ & \\
\hline Referrals to a specialist or physiotherapist & 17.7 & 15.7 & $1.0(0.5-2.0)$ \\
\hline Prescription of medication & 12.9 & 14.9 & $1.1(0.6-2.2)$ \\
\hline Prescription of incontinence pads & 12.1 & 10.5 & $0.6(0.2-1.6)$ \\
\hline
\end{tabular}

Table 2 Relation between patients' gender and initial management of patients with urinary incontinence ( $>25$ years) during the first 3 months after the diagnosis; percentages and OR (F/M)

\section{Gender patient (\%)}

\begin{tabular}{llll}
\cline { 2 - 2 } & $\mathbf{M}(\boldsymbol{n}=\mathbf{1 1 2})$ & $\mathbf{F}(\boldsymbol{n}=\mathbf{5 1 9})$ & OR (95\% CI) \\
\cline { 2 - 3 } & \multicolumn{2}{c}{$0.3(0.1-0.7)^{*}$} \\
Referrals to a specialist or physiotherapist & 7.1 & 19.5 & $0.3(0.3-1.4)$ \\
Prescription of medication & 8.9 & 12.3 & $0.7(0.8-2.9)$ \\
Prescription of incontinence pads & 17.9 & 12.3 & $1.5(0.9$
\end{tabular}

*Significant. 
Gerwen, M.A.G. van, Schellevis, F.G., Lagro-Janssen, A.L.M. Management of urinary incontinence in genera practice: data from the second Dutch National Survey. Journal of Evaluation in Clinical Practice: $2009,15(2)$ 341-345

Table 3 Initial management of female patients with urinary incontinence ( $>25$ years) during the first 3 months after diagnosis by age group (percentages and OR: oldest group used as reference) adjusted for practice differences (multilevel analysis)

Age women Percentage OR (95\% CI)

Referrals to a specialist or physiotherapist $25-59 \quad 29.2 \quad 5.6(2.5-12.5)^{*}$

$60-74 \quad 12.9 \quad 2.1(0.9-5.3)$

$\begin{array}{llll} & \geq 75 & 6.5 & \text { (Reference) } \\ \text { Prescription of medication } & 25-59 & 7.8 & 0.3(0.2-0.7)^{*}\end{array}$

$\begin{array}{llll} & 60-74 & 14.4 & 0.6(0.3-1.3) \\ \text { Prescription of incontinence pads } & \geq 75 & 19.5 & \text { (Reference) } \\ & 25-59 & 5.4 & 0.2(0.1-0.5)^{*} \\ & 60-74 & 18.7 & 0.8(0.3-1.8) \\ & \geq 75 & 19.5 & \text { (Reference) }\end{array}$

Women of 25-59 years of age: $n=257$.

Women of 60-74 years of age: $n=139$.

Women of 75 years and older: $n=123$.

*Significant. 